\title{
Gerenciamento da transferência internacional de tecnologia: estudo de caso na indústria têxtil brasileira
}

\section{Management of international technology transfer: A case study in the Brazilian textile industry}

\author{
Wagner Cezar Lucato ${ }^{1}$ \\ Milton Vieira Júnior ${ }^{1}$ \\ Rosangela Maria Vanalle ${ }^{1}$ \\ Ronaldo Cruz da Silva ${ }^{1}$
}

\begin{abstract}
Resumo: A indústria têxtil brasileira tem enfrentado forte competição por parte de produtos importados a baixos preços da China e de outros países do Extremo Oriente. Para que possam manter a sua habilidade de competir no mercado local, as empresas têxteis brasileiras têm procurado adotar uma estratégia defensiva por meio da busca da diferenciação em seus produtos. Isso vem sendo obtido por meio do desenvolvimento de novos produtos de maior qualidade e de menor custo como decorrência da utilização de novas tecnologias em equipamentos de fabricação. De maneira geral, essas novas tecnologias têm sido transferidas para as empresas brasileiras por fabricantes internacionais de equipamentos têxteis. Assim, este artigo objetiva contribuir para aumentar a competitividade das indústrias têxteis brasileiras para enfrentar as difíceis condições atuais do mercado local por meio da adição de conhecimentos teóricos e de direcionamentos práticos que permitam a elas incrementar a efetividade de seus processos de transferência de tecnologia (TT). Para essa finalidade, realizou-se uma avaliação exploratória de quatro empresas produtoras de tecidos, nas quais tais projetos internacionais de TT tenham sido recentemente efetivados, utilizando-se como framework o modelo Stage-gate de transferência de tecnologia proposto por Jagoda, Maheshwari e Lonseth (2010). Como resultado dessa análise, foi possível identificar similaridades e dissimilaridades entre as práticas de transferência de tecnologia empregadas pelas quatro empresas avaliadas, bem como demonstrar que a utilização de um processo de TT, usando como referencial um modelo Stage-gate, poderia ser empregado para implementar melhorias significativas nas práticas de TT das empresas têxteis brasileiras e, com isso, auxiliá-las no seu árduo esforço para competir eficazmente contra as importações de baixo custo.
\end{abstract}

Palavras-chave: Transferência de tecnologia. Modelo Stage-gate. Indústria Têxtil.

\begin{abstract}
The Brazilian textile industry has been facing fierce competition from low cost imports coming from China and other Far East countries. In order to keep their ability to compete in the local market, Brazilian companies have adopted a product differentiation strategy. This has been achieved by developing new products with better quality at lower costs, characteristics to be provided by new technology in manufacturing equipment. Usually, this new technology is transferred to Brazilian firms by international equipment manufacturers. Hence this paper aims at contributing to increase the competitiveness of Brazilian textile companies by supporting them with theoretical knowledge and practical guidance to allow them to improve the effectiveness of their technology transfer (TT) processes. To this end, we developed an exploratory evaluation of four fabric production companies where technology transfer projects have been implemented, using the Stage-gate model proposed by Jagoda, Maheshwari e Lonseth (2010) as a normative framework. As a result of such analysis, similarities and dissimilarities between the technology transfer practices employed by the four companies evaluated were identified. Also, it was possible to demonstrate that the utilization of a TT process based on a Stage-gate framework could be employed to implement significant improvement in the TT practices used by Brazilian textile companies, which could help them face the fierce competition imposed by the low cost imports from Far East countries.
\end{abstract}

Keywords: Technology transfer. Stage-gate model. Textile industry.

\footnotetext{
${ }^{1}$ Programa de Pós-Graduação em Engenharia de Produção, Universidade Nove de Julho - UNINOVE, CEP 05001-100, São Paulo, SP, Brasil, e-mail: wlucato@uninove.br; mvieirajr@uninove.br; rvanalle@uninove.br; ronaldocruzsilva@yahoo.com.br
}

Recebido em Jun. 12, 2013 — Aceito em Fev. 3, 2014

Suporte financeiro: Os autores agradecem ao Fundo de Apoio à Pesquisa da UNINOVE - Universidade Nove de Julho pelo suporte financeiro necessário para desenvolver este trabalho. 


\section{Introdução}

A crescente competição global, com a rápida integração das economias e a globalização dos produtos, dos mercados e das preferências dos consumidores, tem forçado as empresas a focar com precisão as suas prioridades competitivas. E esse objetivo tem que ser efetivado por meio de uma contínua adaptação das estratégias empresariais a um novo ambiente econômico e social (CHICÁN, 2008). Para isso, tem se reconhecido que a tecnologia é um elemento crítico para sustentar a estratégia global das empresas na sua busca por maior competitividade (FREEMAN, 1974; MILES; SNOW, 1978; MILLER, 1988; PORTER, 1996). Ainda, a transferência de tecnologia (TT) dos países desenvolvidos tem se tornado uma das principais fontes para a melhoria da competitividade dos países em desenvolvimento como o Brasil (DI BENEDETTO; CALANTONE; ZHANG, 2003; WAROONKUN; STEWART, 2008; AUDRETSCH, 2009), onde a indústria têxtil é um importante setor. De fato, o Brasil é o $5^{\circ}$ maior produtor global de produtos têxteis e de vestuário com uma produção anual superior a 9,8 bilhões de peças, cujo valor alcança US\$ 45 bilhões ou 3,5\% do PIB (ASSOCIAÇÃO..., 2012).

Do ponto de vista competitivo, a indústria têxtil do Brasil viveu por muitos anos protegida da concorrência dos demais países, como resultado da adoção de várias barreiras protecionistas que criaram uma reserva de mercado para as empresas têxteis nacionais. Em meados dos anos 90, a supressão da Lei do Similar Nacional, a redução significativa das alíquotas de importação e a eliminação repentina de barreiras não tarifárias trouxeram um grande impacto sobre a indústria nacional na sua tentativa de competir com concorrentes internacionais. Um dos setores que mais foi atingido por esse processo de abertura abrupta da economia foi o têxtil. Tal situação, aliada ao aparecimento de novos competidores com atuação relevante no mercado internacional como China e outros países do Extremo Oriente, tem feito com que as condições competitivas para as empresas têxteis brasileiras se tornassem bastante complicadas nas últimas décadas, na medida em que volumes significativos de produtos importados com preços bastante reduzidos passaram a exercer forte pressão sobre os volumes e margens das empresas nacionais (RANGEL; SILVA; COSTA, 2010).

Para enfrentar esse desafio competitivo, essas empresas têm adotado uma estratégia defensiva que busca diferenciar seus produtos por meio de soluções de maior qualidade a um menor custo (RANGEL; SILVA; COSTA, 2010), por meio da importação de novos equipamentos de produção, pois, no caso das indústrias têxteis, existe um alto grau de dependência de fontes externas de tecnologia de processo (PAVIT, 1984). Porém, de acordo com Lager e Frishammar (2010), quando um equipamento é comprado, a transferência de tecnologia acontece, por definição. Então, pode-se depreender que a melhoria da competitividade das empresas têxteis brasileiras está intimamente associada aos processos de TT que essas firmas utilizam para implementar suas novas tecnologias de produção.

Dessa forma, pretendeu-se com este estudo contribuir com conhecimentos teóricos e recomendações de ordem prática, visando aumentar a competitividade das empresas têxteis brasileiras, fornecendo subsídios para que elas possam melhorar seus processos de transferência de tecnologia (TT) e, com isso, enfrentar de maneira mais efetiva seus atuais desafios competitivos representados por importações de baixo custo oriundas do Extremo Oriente. Deve-se ainda ressaltar que o processo de TT na indústria têxtil brasileira ainda não se constitui em um fenômeno amplamente estudado, até porque, segundo Pavit (1984), as empresas têxteis diversificam mais em produção do que em tecnologia, possivelmente devido a uma complementariedade com outros setores da economia. Por isso, para auxiliar essas empresas a melhorar o seu desempenho na implementação dos seus projetos internacionais de TT, procurou-se, com este trabalho, avaliar como as empresas têxteis nacionais poderiam usar um modelo Stage-gate de transferência de tecnologia, o que foi feito por meio da avaliação exploratória de projetos de transferência internacional de tecnologia, desenvolvidos em quatro empresas do setor têxtil brasileiro, utilizando como referencial o modelo Stage-gate proposto por Jagoda e Ramanathan (2003, 2005, 2009) e Jagoda, Maheshwari e Lonseth (2010).

Para alcançar esse objetivo geral, procurou-se, inicialmente, identificar nas quatro empresas pesquisadas as similaridades e diferenças nas práticas de TT empregadas pelas empresas do setor têxtil no Brasil. Adicionalmente, uma comparação dessas práticas com o modelo Stage-gate utilizado mostrou que ele pode ser adequadamente empregado como um referencial para gerir os processos de TT na indústria têxtil, apesar da identificação de algumas lacunas entre o modelo e as práticas observadas nos estudos realizados. Sugestões para adaptar o modelo Stage-gate para melhorar a sua aplicabilidade aos processos de TT da indústria têxtil foram incluídas neste trabalho. Finalmente, foi possível concluir que a adoção de um processo estruturado de TT, lastreado na utilização de um modelo Stage-gate, poderia constituir-se em ferramenta relevante de apoio na implementação de projetos internacionais de TT destinados a melhorar a posição competitiva das empresas têxteis brasileiras. 


\section{Referencial teórico}

De acordo com Takahashi (2005), a TT pode ser definida como um processo entre duas entidades sociais no qual o conhecimento tecnológico é adquirido, desenvolvido, usado e melhorado por meio da transferência de componentes tecnológicos com o propósito de implementar um processo, um elemento de um produto, o próprio produto ou uma metodologia. Há ainda dois pré-requisitos para a TT ocorrer: quem faz a cessão deve estar disposto a transferir a tecnologia e quem a recebe deve estar disposto a absorver, adaptar e melhorar a tecnologia transferida. Rogers, Takegami e Yin (2001, p. 254) definem a TT como "o movimento da inovação tecnológica de uma organização de $\mathrm{P} \& \mathrm{D}$ para uma organização receptora".

O processo de desenvolver a capacidade tecnológica varia nos países desenvolvidos e nos emergentes (BENNETT; ZHAO, 2004; ERENSAL; ALBAYRAK, 2008). Nas economias desenvolvidas, o processo se inicia com a concepção tecnológica e envolve a sua adaptação, absorção e negociação. Em seguida, os empreendedores trocam gradualmente a exportação de produtos pelo processo de transferência das instalações fabris para as nações em desenvolvimento. Nos países emergentes, a capacidade tecnológica é desenvolvida de modo diferente: ela começa com a negociação da nova tecnologia com seus desenvolvedores originais. Com o início da produção local, o conhecimento tecnológico é absorvido e adaptado para as condições locais (TAKAHASHI, 2005).

Barbieri e Álvares (2005) afirmam que a transferência de tecnologia pode ser alcançada diretamente (a tecnologia vem embutida em equipamentos, instalações, instrumentos, peças e/ ou componentes), indiretamente (patentes, desenhos e outro documentos) ou por meio de uma combinação dessas duas formas. O sucesso do processo de TT pode ser avaliado: pelo desempenho econômico, pelo desempenho no mercado, pelo desempenho do produto, pelo domínio econômico obtido ou pela satisfação com a nova tecnologia. Sob a perspectiva do recebedor, os resultados dependem de um conjunto de fatores relevantes (internos e externos) para o sucesso da transferência de tecnologia: infraestrutura; competitividade; cultura organizacional; capacidade de absorção; experiência no processo de TT; e capacidade gerencial (TAKAHASHI; SACOMANO, 2002; CHANG et al., 2009).

\subsection{Modelos de transferência de tecnologia}

Uma revisão da literatura indicou que diferentes modelos de TT têm sido propostos desde os anos de 1950. No Quadro 1, faz-se uma síntese dos modelos de TT mais relevantes mencionados na literatura com destaque para os seus autores, para o período no qual esses referenciais foram propostos ou utilizados e para as respectivas ideias centrais de cada um.

Nesse ponto, é relevante mencionar que este trabalho também objetivou propor um processo mais efetivo de TT a ser adotado pelas empresas têxteis do Brasil, como forma de suportá-las em seu reposicionamento competitivo por meio da modernização de sua base tecnológica. Dentre todos os modelos de TT considerados, este trabalho propõe avaliar a utilização do modelo Stage-gate originalmente proposto por Jagoda e Ramanathan, como o referencial a ser empregado para efetivamente melhorar o processo de TT das empresas têxteis brasileiras. Por isso, descreve-se em maior detalhe as características desse modelo.

\subsection{O modelo Stage-gate de Jagoda e Ramanathan}

Como já mencionado, este trabalho utiliza como referência o modelo Stage-gate proposto por Jagoda e Ramanathan $(2003,2005,2009)$ e Jagoda, Maheshwari e Lonseth (2010), cuja descrição sumarizada é ilustrada na Figura 1.

O stage 1 envolve a identificação das oportunidades e a determinação da tecnologia adequada ao fim a que se destina. De acordo com os autores, a melhor maneira de começar essa fase é por meio da análise dos mercados nos quais a empresa opera e por meio da identificação das tecnologias utilizadas pelos competidores.

Depois da conclusão do stage 1 e antes de caminhar no processo de TT, deve-se conduzir uma avaliação crítica por meio do gate 1 - confirmação da tecnologia identificada. Jagoda, Maheshwari e Lonseth (2010) explicam que, neste ponto, as tecnologias identificadas são avaliadas considerando-se vários critérios como a adequação da tecnologia às estratégias do negócio, as capacitações requeridas, os riscos envolvidos etc. Com base nessa avaliação, o time encarregado desse gate decide se o projeto prossegue, se é refeito ou até se é descontinuado.

O stage 2 concentra-se na busca da tecnologia necessária. Aqui se começa a alocar substanciais recursos para o projeto de TT. Como resultado das recomendações feitas no gate 1 , um conjunto de especificações claras deve ser montado com relação à tecnologia selecionada. Ainda, os fornecedores potenciais dessa tecnologia são identificados e contatados.

Jagoda, Maheshwari e Lonseth (2010) indicam que o gate 2 trata da confirmação do projeto. Este é um gate crítico porque está relacionado com a decisão crítica que envolverá substancial alocação de recursos. O processo de avaliação se inicia pelo 
Quadro 1. Modelos relevantes de TT considerados.

\begin{tabular}{|c|c|c|c|}
\hline Referência & Modelo & Ano & Ideia Central do Modelo \\
\hline \multirow{4}{*}{ Gibson e Slimor (1991) } & Apropriabilidade & $1945 / 1950$ & $\begin{array}{l}\text { Quando uma nova tecnologia é desenvolvida } \\
\text { e dada a conhecer por meio de relatórios ou } \\
\text { periódicos profissionais, os usuários contatarão } \\
\text { os pesquisadores para utilização da tecnologia. }\end{array}$ \\
\hline & Disseminação & $1960 / 1970$ & $\begin{array}{l}\text { Um especialista fará a transferência de } \\
\text { conhecimento específico para o seu usuário } \\
\text { potencial, assumindo que, quando as conexões } \\
\text { apropriadas são estabelecidas, a nova tecnologia } \\
\text { flui do especialista para o usuário como a água } \\
\text { em um cano quando se abre uma torneira. }\end{array}$ \\
\hline & $\begin{array}{l}\text { Utilização do } \\
\text { conhecimento }\end{array}$ & $1980 \mathrm{~s}$ & $\begin{array}{l}\text { Enfatiza o importante papel da comunicação } \\
\text { interpessoal entre os desenvolvedores da } \\
\text { tecnologia e seus usuários, bem como a } \\
\text { importância das barreiras organizacionais ou } \\
\text { facilitadores do processo de TT. }\end{array}$ \\
\hline & Integração & $1990 \mathrm{~s}$ & $\begin{array}{l}\text { Integra o desenvolvimento da tecnologia, sua } \\
\text { aceitação e aplicação com as atividades que } \\
\text { foram consideradas nos modelos tradicionais. }\end{array}$ \\
\hline Williams e Gibson (1990) & Comunicação & $1990 \mathrm{~s}$ & $\begin{array}{l}\text { Considera a TT como um fluxo no qual existe } \\
\text { um processo contínuo e simultâneo de troca de } \\
\text { ideias entre todas as partes envolvidas. }\end{array}$ \\
\hline $\begin{array}{l}\text { Rebentisch e Ferretti } \\
\text { (1995) }\end{array}$ & $\begin{array}{l}\text { Competências } \\
\text { organizacionais }\end{array}$ & $1990 \mathrm{~s}$ & $\begin{array}{l}\text { Focada em quanto esforço é requerido para } \\
\text { transferir os diferentes tipos de tecnologia e } \\
\text { qual o impacto das competências atuais da } \\
\text { organização sobre o processo de TT. }\end{array}$ \\
\hline Sung e Gibson (2000) & Limitação & $2000 \mathrm{~s}$ & $\begin{array}{l}\text { Propõe explicações razoáveis para os fatores que } \\
\text { afetam o conhecimento e a TT, considerando } \\
\text { quarto níveis de envolvimento: criação de } \\
\text { tecnologia e conhecimento; sua distribuição; } \\
\text { implementação; e comercialização. }\end{array}$ \\
\hline Malik (2002) & Rádio difusão & $2000 \mathrm{~s}$ & $\begin{array}{l}\text { A transferência de tecnologia interempresas } \\
\text { envolve um processo interativo de duas vias e } \\
\text { não um de mão única. }\end{array}$ \\
\hline Guan et al. (2006) & $\begin{array}{l}\text { Evolução tecnológica } \\
\text { para os BRICS }\end{array}$ & $2010 \mathrm{~s}$ & $\begin{array}{l}\text { Evolui da imitação para a inovação que inclui } \\
\text { três fases progressivas e distintas: aquisição, } \\
\text { assimilação e melhoria da tecnologia. }\end{array}$ \\
\hline Choi (2009) & Árvore & $2010 \mathrm{~s}$ & $\begin{array}{l}\text { Compara o modelo de TT a uma árvore e o } \\
\text { objetivo é gerar inovações (frutos). }\end{array}$ \\
\hline $\begin{array}{l}\text { Jagoda e Ramanathan } \\
(2003,2005,2009)\end{array}$ & Stage-gate & $2010 \mathrm{~s}$ & $\begin{array}{l}\text { O processo de TT é dividido em atividades } \\
\text { multifuncionais chamadas de stages (estágios). } \\
\text { Depois de cada stage, há um ponto de } \\
\text { verificação ou gate (portão) no qual questões } \\
\text { críticas são levantadas para validar o stage } \\
\text { imediatamente anterior. }\end{array}$ \\
\hline
\end{tabular}

exame das alterativas de tecnologia propostas pelos diferentes potenciais fornecedores.

O stage 3 envolve a negociação da tecnologia. Esta é uma fase relevante porque um problema frequente no processo de TT refere-se ao valor da tecnologia a ser adquirida. Ainda, o preço final da tecnologia dependerá do poder de negociação de cada uma das partes envolvidas (NAGAOKA, 2009). Nesse estágio, geralmente, ocorre um intenso processo de comunicação entre o fornecedor e o recebedor da tecnologia.

Para verificar a adequação do desenvolvimento do stage 3, no gate 3, a finalização e a aprovação do contrato de fornecimento da tecnologia são realizadas. Esse gate inicia-se quando as negociações chegam a bom termo e ambas as partes estão dispostas a preparar um contrato que estabeleça formalmente as condições acertadas entre elas. $\mathrm{O}$ produto final 


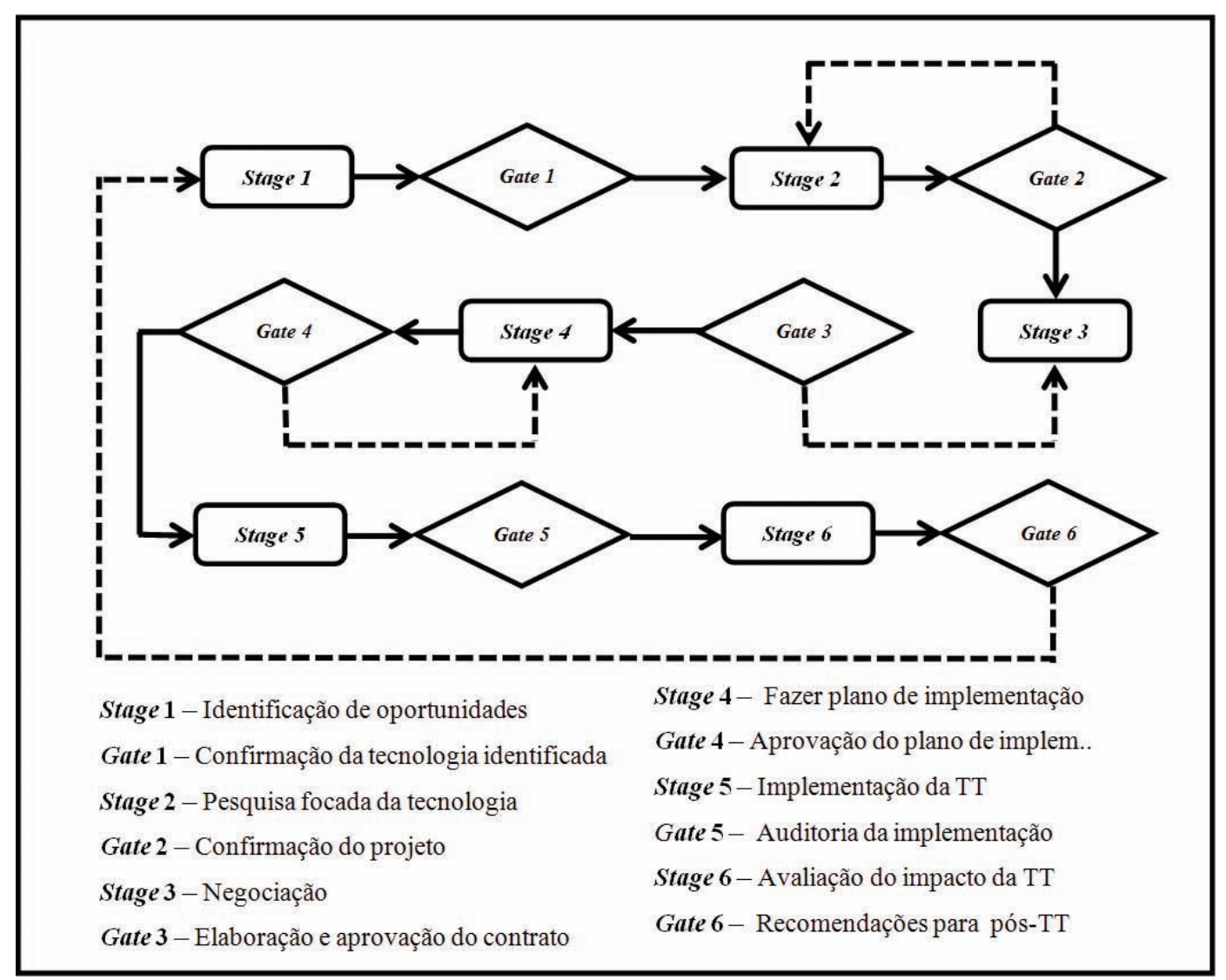

Figura 1. Resumo do modelo de TT proposto por Jagoda and Ramanathan (adaptado de Jagoda, Maheshwari e Lonseth (2010)).

deste gate é o contrato de fornecimento da tecnologia firmado por ambas as partes contratantes.

No stage 4, o foco se concentra na preparação do plano de implementação do projeto de TT. Aqui a organização se prepara para receber a nova tecnologia e a equipe encarregada do projeto de TT prepara um plano detalhado de implementação com todas as atividades necessárias, incluindo os treinamentos requeridos, os cronogramas, os recursos e as responsabilidades correspondentes.

O gate 4 está relacionado à aprovação do plano de implementação. Neste caso, a equipe da TT realiza uma ampla avaliação do cronograma do projeto levando em consideração o que ficou acertado com o fornecedor da tecnologia. De acordo com Jagoda, Maheshwari e Lonseth (2010), atenção especial deve ser dada para a adequação dos treinamentos, para a adequação da infraestrutura, para a duração das atividades e para os prazos de pagamento do fornecedor. Se todos os aspectos analisados forem favoráveis, é dada a aprovação para o projeto evoluir para o próximo estágio.

O stage 5 envolve a efetiva implementação do projeto de TT. O sucesso desta fase depende de uma boa gestão de projeto e de uma boa cooperação com o fornecedor da tecnologia. Um bom controle da chegada de materiais, peças e serviços relacionados à nova tecnologia é um fator-chave para o sucesso da implementação.

Antes de avançar no projeto de TT, o gate 5 deverá fazer uma auditoria da implementação realizada. Nesse ponto, o cronograma original das atividades e metas planejadas para o projeto de TT é comparado aos resultados reais obtidos durante a implementação. $\mathrm{O}$ objetivo aqui é entender eventuais barreiras que possam ter sido encontradas nesse processo.

Deois da implementação do projeto de TT, o processo de transferência poderia ser considerado terminado. Contudo, Jagoda, Maheshwari e Lonseth (2010) recomendam um stage adicional, o de número 6 , no qual se realiza a avaliação do impacto da transferência de tecnologia realizada. Os impactos a serem considerados deveriam incluir várias perspectivas: financeira, de mercado, tecnológica e organizacional, mas essa tarefa nem sempre é fácil porque muitos dos resultados da TT somente se materializarão ao longo da vida do projeto. Ademais, deve-se também considerar que projetos de TT, não raro, envolvem benefícios intangíveis que não são fáceis de mensurar. 
De acordo com o modelo Stage-gate proposto por Jagoda and Ramanathan, o processo de TT encerra-se no gate 6 , no qual as recomendações para as atividades pós-TT são estabelecidas. O objetivo aqui é avaliar se a empresa deveria continuar a usar o mesmo processo de transferência de tecnologia ou, ao invés disso, buscar outras formas mais eficientes de TT. No entanto, Jagoda, Maheshwari e Lonseth (2010) afirmam que o sucesso na implementação de projetos de TT, em geral, cria uma parceria estreita entre as partes envolvidas que pode levar a novos projetos futuros para alavancar a competitividade da empresa, utilizando a mesma abordagem que se mostrou adequada num primeiro momento.

\subsection{O processo de TT na indústria têxtil brasileira}

A indústria têxtil no Brasil pode ainda ser considerada como um setor em desenvolvimento. Historicamente, intensiva em mão de obra, a indústria está gradualmente se tornando intensiva em capital como resultado da utilização crescente de equipamentos e sistemas automatizados (BRAGA JUNIOR; ANTUNES; PIO, 2009). Em adição, práticas modernas de gestão da produção como TQC (Controle da Qualidade Total), JIT (Just-in-Time) e manufatura enxuta têm sido adotadas por muitas empresas no setor (LOBO, 1997). Lima (2007) menciona que as melhorias de tecnologia que são implementadas no setor têxtil resultam da aquisição de novos equipamentos destinados a substituir processos e máquinas obsoletos. Contudo, Prochnik (2003) indica que, apesar dos significantes investimentos feitos, a indústria têxtil brasileira ainda necessita de uma atualização mais agressiva de sua base tecnológica para se tornar internacionalmente competitiva. De acordo com Braga Junior, Antunes e Pio (2009), o desenvolvimento da tecnologia na indústria têxtil tem sido feita primordialmente pelos fornecedores de insumos e de equipamentos, confirmando as conclusões estabelecidas por Pavit (1984). Já Rangel, Silva e Costa (2010, p. 167) complementam afirmando que, em termos de tecnologia, o setor têxtil é

uma indústria absorvedora de tecnologia em que as inovações tecnológicas são exógenas, ou seja, é a indústria de máquinas e equipamentos que promove as inovações do processo produtivo.

Para Braga Junior, Antunes e Pio (2009), as atividades de $P \& D$ nas empresas têxteis são limitadas ao acompanhamento das tendências de mercado e à criação de novos artigos têxteis. O desenvolvimento de novos produtos é feito em conjunto com os fornecedores das novas tecnologias. Nas empresas grandes e médias, o processo de aquisição de tecnologia é feito por um comitê composto por representantes da alta administração, da supervisão e do departamento de criação. Porém, pode-se notar que aquelas companhias, em geral, não possuem uma estratégia formal de renovação tecnológica, sendo a mudança ou aquisição de nova tecnologia uma ação reativa e aleatória. Nesse processo, as empresas de porte grande e médio, na maioria das vezes, acabam vendendo os equipamentos substituídos para as companhias menores, sendo esse processo basicamente uma oportunidade para que as pequenas empresas têxteis possam atualizar suas bases tecnológicas.

Pavit (1984) e também Braga Junior, Antunes e Pio (2009) afirmam que no Brasil o processo de TT é comandado pelos fornecedores por meio da venda de produtos e/ou equipamentos com posterior assistência técnica. Os fornecedores são responsáveis pela implementação das novas tecnologias por meio do adequado treinamento do pessoal de seu cliente para a correta utilização da tecnologia transferida. Ivarsson e Alvstam (2004) investigaram o processo de TT nos BRICS, identificando que relacionamentos de longo prazo lastreados em confiança mútua são relevantes para a colaboração e aprendizado entre o fornecedor da tecnologia e seu usuário. Esse relacionamento é geralmente amigável e envolve certo grau de parceria (LAGER; FRISHAMMAR, 2010).

Segundo Braga Junior, Antunes e Pio (2009), não há um processo comum para a TT na indústria têxtil brasileira devido à grande amplitude de tecnologias empregadas e à diversidade estrutural que é observada nesse setor. Ainda assim, eles mencionam o processo genérico que é estabelecido como consequência das práticas mais frequentes observadas nessa indústria, o que confirma os resultados obtidos por Stock e Tatikonda (2004, 2008). Esse processo envolveria cinco etapas: a) identificação da nova tecnologia necessária para atender a uma nova demanda do mercado, um novo produto ou um novo processo de fabricação; b) verificação da efetividade da tecnologia escolhida por meio de visitas a outras empresas, nas quais essa tecnologia esteja sendo usada; c) compra da nova tecnologia na forma de novo equipamento, novo processo químico ou novas fibras; d) preparação da implementação da tecnologia por meio de treinamentos intensivos realizados na própria empresa ou nas instalações do fornecedor (LOBO, 2007); e e) implementação da nova tecnologia com assistência técnica e suporte fornecido pelo fornecedor.

\section{Questões de pesquisa, metodologia e descrição dos estudos de caso}

Antes de examinar os estudos de caso, é relevante descrever as questões de pesquisa a serem consideradas pelo presente trabalho, bem como a metodologia aplicada e as características das empresas selecionadas para suportar a presente pesquisa. 


\subsection{Questões de pesquisa e metodologia}

Como mencionado anteriormente, o propósito central deste artigo é contribuir com o aumento da competitividade das empresas têxteis brasileiras por meio da geração de conhecimentos teóricos e orientações de ordem prática sobre como elas poderiam valer-se de um modelo Stage-gate para melhorar seus processos de transferência de tecnologia. Para alcançar esses objetivos, três questões de pesquisa $(Q P)$ foram consideradas:

- QP1. Como as práticas de TT nas empresas têxteis podem ser agrupadas de maneira que um processo típico de TT possa ser identificado?

- QP2. Como um modelo Stage-gate de TT pode ser efetivamente aplicado às empresas têxteis para gerenciar esse processo? O modelo referencial Stage-gate proposto por Jagoda e Ramanathan seria uma alternativa viável para as empresas têxteis utilizarem?

- QP3. Que modificações no modelo de Jagoda e Ramanathan seriam necessárias para melhor adequá-lo aos requisitos do setor têxtil?

Para responder a essas questões, este artigo investigou as práticas de transferência de tecnologia em quatro empresas do setor têxtil brasileiro. O método do estudo de caso foi usado porque a pesquisa aqui desenvolvida trata de questões do tipo "como / porque" e também investiga um fenômeno contemporâneo no contexto do mundo real no qual as fronteiras entre o fenômeno e o contexto não estão claras (YIN, 2009). Para selecionar as empresas consideradas nos estudos de caso, Patton (1990) recomenda a utilização de amostras com conteúdo (purposeful sampling), isto é, casos dos quais o pesquisador possa extrair quantidade significativa de informações relevantes sobre os temas centrais em estudo. Dentre as várias estratégias sugeridas por Patton (2009) para selecionar as amostras com conteúdo, este artigo considera a amostragem de casos típicos, na qual as empresas a serem selecionadas para análise deveriam apresentar projetos comparáveis de transferência de tecnologia. Em linha com essa abordagem, foram estabelecidos quatro critérios para a seleção das empresas que iriam compor os estudos de caso: a) elas deveriam estar localizadas em um mesmo polo produtor têxtil no Brasil; b) elas deveriam produzir o mesmo tipo básico de produto já que na indústria têxtil muitas alternativas existem (por exemplo: fiações, produção de tecidos, tingimento e confecções) e produtos diferentes requerem diferentes práticas de TT; c) elas deveriam ter implementado projetos de TT semelhantes, pois projetos diferentes podem exigir diferentes abordagens em relação à transferência de tecnologia (COCCIA, 2008); e d) elas deveriam ser diferentes em porte, para poder verificar se as práticas de TT mudam significativamente dependendo do tamanho da empresa.

\subsection{Detalhes dos casos estudados}

Seguindo os critérios acima enunciados, quatro empresas brasileiras do setor têxtil localizadas no polo de Americana, São Paulo, foram escolhidas conforme detalhes sumarizados na Tabela 1. Informações adicionais são apresentadas mais à frente. Como procedimento para a coleta de dados nas empresas selecionadas, escolheu-se a entrevista semiestruturada porque ela é considerada a melhor alternativa quando se realiza pesquisa qualitativa baseada em estudos de caso (BRYMAN, 1995; COLLINS; HUSSEY, 2003). Para guiar as entrevistas e assegurar que um mesmo conteúdo fosse abordado em todas elas, um aide-memoire foi preparado contendo as perguntaschave e questões relevantes a serem consideradas nas entrevistas. Os principais tópicos enfocados foram: a) informações gerais sobre a empresa; b) informações gerais sobre o projeto de TT considerado; c) detalhes sobre o planejamento e a implementação do projeto de TT. Para cada um desses aspectos, um conjunto específico de perguntas foi preparado. No entanto, essas questões serviram apenas para se iniciar as discussões sobre determinado tema, já que os

Tabela 1. Empresas selecionadas e respectivos projetos de TT.

\begin{tabular}{|c|c|c|c|c|c|c|c|c|}
\hline Empresa & Fundação & $\begin{array}{c}\text { Natureza } \\
\text { do } \\
\text { capital } \\
\end{array}$ & $\begin{array}{c}\text { Vendas } \\
\text { anuais } \\
\text { (R\$ MM) }\end{array}$ & $\begin{array}{l}\text { No. de } \\
\text { empreg. }\end{array}$ & $\begin{array}{l}\text { No. de } \\
\text { teares }\end{array}$ & $\begin{array}{l}\text { Produto } \\
\text { principal }\end{array}$ & Mercados & $\begin{array}{c}\text { Projeto de } \\
\text { TT }\end{array}$ \\
\hline A & 1966 & $\begin{array}{c}\text { Familiar } \\
\text { Brasil }\end{array}$ & 34 & 220 & 60 & $\begin{array}{l}\text { Tecido plano } \\
\text { (cama e mesa) }\end{array}$ & $\begin{array}{c}95 \% \\
\text { doméstico }\end{array}$ & $\begin{array}{c}\text { Aquisição de } \\
6 \text { teares }\end{array}$ \\
\hline B & 1985 & $\begin{array}{c}\text { Familiar } \\
\text { Brasil }\end{array}$ & 60 & 150 & 32 & $\begin{array}{c}\text { Tecidos } \\
\text { tubulares em } \\
\text { malha }\end{array}$ & $\begin{array}{c}100 \% \\
\text { doméstico }\end{array}$ & $\begin{array}{c}\text { Aquisição de } \\
8 \text { teares }\end{array}$ \\
\hline $\mathrm{C}$ & 1969 & $\begin{array}{c}\text { Familiar } \\
\text { Brasil }\end{array}$ & 450 & 2.000 & 700 & $\begin{array}{c}\text { Tecido plano } \\
\quad \text { (jeans) }\end{array}$ & $\begin{array}{c}90 \% \\
\text { doméstico }\end{array}$ & $\begin{array}{l}\text { Aquisição de } \\
70 \text { teares }\end{array}$ \\
\hline $\mathrm{D}$ & 1968 & $\begin{array}{c}\text { Familiar } \\
\text { Brasil }\end{array}$ & 20 & 70 & 40 & $\begin{array}{c}\text { Tecido plano } \\
\text { (decoração) }\end{array}$ & $\begin{array}{c}100 \% \\
\text { doméstico }\end{array}$ & $\begin{array}{c}\text { Aquisição de } \\
12 \text { teares }\end{array}$ \\
\hline
\end{tabular}


pesquisadores conduziram as entrevistas nas direções consideradas mais relevantes para obter o detalhamento das informações julgadas necessárias.

Para explorar as práticas de TT nas quatro empresas selecionadas, foram realizadas entrevistas aprofundadas com os executivos que estavam diretamente envolvidos com os projetos de TT. Aspectos estratégicos relacionados à transferência de tecnologia foram discutidos com os Gerentes Gerais ou Diretores, conforme o caso. As entrevistas foram conduzidas em meados de 2012. As respostas dos entrevistados foram anotadas pelos pesquisadores e depois transcritas para comparação e análise. As informações gerais sobre as entrevistas vão a seguir.

$\mathrm{Na}$ Empresa A as entrevistas foram feitas com o Engenheiro-Chefe que estava encarregado de implementar o projeto de TT estudado e com o Gerente Geral, também proprietário da empresa. As entrevistas estenderam-se por quase um dia e incluíram uma detalhada visita às instalações industriais na qual os detalhes do projeto de TT foram apresentados e discutidos com os pesquisadores. Em anos recentes, por causa da valorização do Real, a empresa A vem enfrentando uma competição severa por parte de produtos de baixo custo oriundos principalmente da China e do Paquistão. Assim, a estratégia central da empresa tem sido tornar-se competitiva contra as importações. Para isso, ela decidiu melhorar a sua base tecnológica por meio da aquisição de seis teares a jato de ar de última geração com o objetivo de acelerar seu ritmo de produção, ao mesmo tempo que obteria produtos de melhor qualidade e de menor custo. Essa importação de equipamentos e sua consequente colocação em marcha foi o objetivo da pesquisa de TT nessa empresa.

Na Empresa B, seu proprietário e também Gerente Geral dedicou cerca de quatro horas conversando com os pesquisadores sobre sua empresa e sobre o projeto de TT objeto deste estudo. Também esta firma vem competindo com dificuldades com os produtos importados da China e também com artigos produzidos por pequenos fabricantes locais, o que tem afetado de maneira decisiva suas margens e lucros. A estratégia que a empresa identificou para contornar essas dificuldades foi a mudança de sua linha de produtos para itens de maior valor agregado nos quais a competição é menos intensa e as margens mais favoráveis. Para implementar essa estratégia, a empresa B identificou a necessidade de melhorar a sua base tecnológica como forma de viabilizar a introdução de produtos mais sofisticados, com níveis de qualidade mais elevados e menor custo. Para isso, a empresa decidiu importar 8 novos teares tubulares que foram os objetivos da presente pesquisa de TT.

A Empresa $\mathbf{C}$ é a terceira maior produtora brasileira de tecidos jeans. Devido ao seu tamanho, a empresa possui uma gerência profissional em todas as áreas da organização. As discussões envolveram os diretores Industrial e Comercial, que são os responsáveis pelos projetos de TT e pela execução da estratégia competitiva, respectivamente. A entrevista foi desenvolvida ao longo de meio dia. Da mesma forma que as demais firmas do setor têxtil brasileiro, a empresa $\mathrm{C}$ vem enfrentando uma forte concorrência por parte de produtos importados da China, do Paquistão, da Turquia e do Leste Europeu. Por isso, a estratégia central da empresa tem sido a criação de diferenciação em relação à concorrência, composta majoritariamente por produtos de baixo custo e qualidade duvidosa. Assim, seu foco tem sido a fabricação de produtos premium destinados ao mercado de confecção de jeans. Essa estratégia tem obtido resultado relevante à medida que tem sustentado um crescimento anual contínuo entre $10 \%$ e $15 \%$, como decorrência do crescimento do mercado local aliado a um aumento de sua participação nesse mercado. Para implementar essa estratégia, a empresa adquiriu recentemente 70 teares a jato de ar, sendo essa aquisição o objeto do presente estudo.

Na Empresa D, devido a seu porte, seu proprietário e também Gerente Geral é a pessoa responsável por todo o processo de transferência de tecnologia. Em uma entrevista que durou cerca de 4 horas, foi possível verificar que a estratégia central da empresa em essência não difere das adotadas pelas outras três investigadas neste trabalho. Para fugir da forte competição imposta por produtos de baixo custo vindos do Extremo Oriente, a empresa D decidiu focar sua produção em tecidos planos destinados à decoração como forma de obter uma diferenciação em relação à concorrência. A exemplo de muitas pequenas empresas têxteis brasileiras, essa empresa compra os equipamentos disponibilizados por firmas de maior porte quando da sua substituição por itens mais novos. Recentemente, a empresa D comprou 12 teares a jato de ar da empresa $\mathrm{C}$ como uma forma de melhorar seus níveis de qualidade e de reduzir custos. Essa aquisição foi o objeto desta pesquisa.

Como se observa pela análise dos casos considerados, o tipo de equipamento adquirido como parte dos projetos de TT deve ser considerado como de baixa complexidade tecnológica quando comparado com outros projetos mais sofisticados de transferência de tecnologia (STOCK; TATIKONDA, 2004, 2008).

\section{Análise do processo de TT: similaridades e diferenças}

Por meio da análise dos resultados obtidos no campo e da comparação dos processos de TT desenvolvidos pelas 4 empresas pesquisadas, foi possível identificar diversas similaridades e algumas diferenças entre elas.

Inicialmente a pesquisa pôde confirmar uma afirmação feita por Pavit (1984) e por Braga Junior, 
Antunes e Pio (2009) na qual os fornecedores têm sido responsáveis pelo desenvolvimento da tecnologia no setor têxtil. De fato, as quatro empresas investigadas desenvolveram ações de TT envolvendo a aquisição de novos equipamentos de produção. Como já mencionado, Lager e Frishammar (2010) afirmam que, quando um equipamento é comprado, a transferência de tecnologia acontece, por definição.

Para as quatro empresas pesquisadas, os processos de TT tiveram como objetivo a aquisição de novos equipamentos para atender a uma prioridade estratégica comum: melhorar a competitividade para enfrentar uma forte competição por parte de produtos de baixo custo oriundos da China e de outros países do Extremo Oriente (KUMAR; ARBI, 2007). Todas as quatro empresas indicaram que a maior capacidade de competição viria da diferenciação, isto é, de novos produtos fabricados com níveis maiores de qualidade e com menor custo. Essas vantagens seriam conseguidas mediante a obtenção de novas tecnologias por meio da aquisição de novos equipamentos. As quatro empresas pesquisadas já tinham tido experiência prévia com outros projetos de TT similares aos aqui considerados.

As quatro empresas indicaram valerem-se de visitas a feiras têxteis nacionais e internacionais, bem como utilizarem contatos frequentes com os representantes locais dos fabricantes de equipamentos como as principais fontes de informação sobre novas tecnologias, fazendo da comunicação uma aspecto-chave no relacionamento cliente-fornecedor, confirmando assim os resultados das pesquisas realizadas por Rahman e Bennett (2009). Ressalte-se também que, em três das quatro firmas (B, C e D), toda a busca por nova tecnologia e a decisão de que equipamento comprar são feitas pessoalmente pelos Gerentes Gerais (e também proprietários). Na empresa A, outros executivos participam da avaliação, mas a decisão final na seleção e a negociação da nova tecnologia também são feitas pelo $C E O /$ proprietário. Esse cenário poderia ser caracterizado como inerente às empresas familiares brasileiras e não somente às empresas do setor têxtil, como destacado por Lucato e Vieira Junior (2006).

Para buscar novas tecnologias, todas as quatro empresas buscaram identificar os equipamentos mais adequados para produzir os novos produtos necessários para o seu reposicionamento competitivo. Antes de uma decisão final ser tomada, desenvolveram extensas discussões técnicas com os fornecedores e/ou seus representantes locais. As empresas A e B utilizaram-se de visitas às plantas de concorrentes para verificar os equipamentos propostos em operação e poder, assim, confirmar que as recomendações dos fornecedores iriam gerar na prática os benefícios indicados. Já a empresa $\mathrm{C}$ adota abordagem diferente. Devido à grande quantidade de equipamentos adquiridos de cada vez, ela geralmente compra duas ou três unidades do novo equipamento e as coloca em operação em sua planta para verificar a adequação dessa solução aos seus objetivos produtivos. De maneira geral, todas as empresas pesquisadas utilizam parcos recursos em termos de tecnologia da informação (TI) no processo de seleção dos novos equipamentos.

O processo de especificação da tecnologia é bastante similar para três das empresas pesquisadas, nas quais os produtos e seus objetivos de produção constituem-se na informação básica para orientar a busca pelos novos equipamentos. A empresa C, por outro lado, possui consultores internacionais que fazem recomendações sobre os maquinários a serem adquiridos em função dos novos produtos a serem desenvolvidos. As empresas A e B enviam suas especificações de produtos para os fabricantes internacionais de equipamentos por meio dos seus representantes locais, que centralizam todos os contatos, discussões e negociações. A empresa $\mathrm{C}$, ao contrário, envia as especificações dos equipamentos necessários diretamente aos fabricantes internacionais. Nesse caso, o representante local é usado somente como um suporte adicional, quando necessário. Devido ao fato da empresa $\mathrm{D}$ adquirir somente equipamentos de segunda mão, sua busca por novas tecnologias envolve contatos constantes com as empresas de maior porte localizadas na mesma região, para verificar a disponibilidade de máquinas usadas que possam ser adequadas aos novos tipos de tecidos a serem feitos. Como se observa, a atuação do representante local do fabricante internacional de equipamentos é vital para as empresas A e B. Já a empresa C depende fortemente do próprio fabricante, e a empresa $\mathrm{D}$, do vendedor do equipamento usado.

Durante as entrevistas foi possível observar que as quatro empresas usam a mesma abordagem para classificar seus potenciais fornecedores: o primeiro critério é a identificação daqueles fornecedores que oferecem a melhor solução técnica para a fabricação dos produtos por elas especificados. Dentre aqueles com soluções de tecnologias consideradas adequadas, o fornecedor com as condições comerciais mais favoráveis é escolhido para uma negociação final. Somente a empresa $\mathrm{C}$ aplica um critério adicional. Ela considera a padronização de seu parque de teares como um pré-requisito para a seleção da alternativa a ser escolhida, antes das considerações comerciais. As empresas pesquisadas não utilizam recursos de TI para a identificação e seleção de fornecedores.

Uma vez que o fornecedor do equipamento é escolhido, ocorrem três processos distintos de negociação. As empresas A e B apoiam-se totalmente no representante local do fabricante internacional selecionado. Nesse processo, finaliza-se a especificação detalhada do equipamento escolhido e as condições comerciais são negociadas até que se estabeleça um acordo final entre as partes. Como resultado dessas 
negociações, uma proposta técnico-comercial final é elaborada pelo representante local. Com base nessa proposta, a empresa compradora emite a respectiva ordem de compra para a nova tecnologia. A empresa C segue um processo similar, mas as negociações são feitas diretamente com o fabricante internacional, sem intermediação de seu representante local. Devido à peculiaridade das aquisições feitas pela empresa $\mathrm{D}$, ela interage diretamente com o vendedor do equipamento, usualmente uma firma maior localizada na mesma região geográfica. Neste caso, as negociações são feitas "de proprietário para proprietário" envolvendo um grau bastante reduzido de formalização. As quatro empresas não indicaram maiores dificuldades nesses processos de negociação, cujos prazos variaram de duas semanas (empresa D) a oito meses (empresa A). $\mathrm{B}$ e $\mathrm{C}$ indicaram períodos intermediários de quatro meses em média, nos dois casos.

A comunicação entre as partes que negociam envolvem discussões face a face, contatos telefônicos e muitos $e$-mails. Barreiras de linguagem, de cultura e organizacionais não têm sido limitações porque as empresas A, B e D interagem diretamente com os representantes locais (ou proprietários das empresas maiores). A empresa $\mathrm{C}$ mantém contatos diretos com os fabricantes internacionais. Como todas as negociações são conduzidas pelo seu Diretor Geral, que é fluente em inglês e tem larga experiência em negociações internacionais, não foram reportadas dificuldades nesse processo. Com exceção de e-mails, nenhum outro recurso de TI é utilizado nos processos de negociação das novas tecnologias.

Todas as empresas pesquisadas desenvolveram algum tipo de plano de implementação para suas respectivas transferências de tecnologia, que variaram entre um cronograma informal preparado pelo Gerente Geral na empresa D e uma lista bastante detalhada de ações a serem executadas e seu respectivo cronograma formal, preparados pelas equipes de implementação de TT nas outras três firmas. Nas empresas A, B e $\mathrm{C}$, os planos de implementação foram devidamente revisados e aprovados pelos respectivos Gerentes Gerais. As quatro empresas também identificaram a necessidade de treinar empregados adicionais para operar os novos equipamentos, mesmo antes da chegada destes, já que nenhuma delas possuía pessoal suficiente para isso. As ferramentas de TI empregadas no planejamento da implementação se limitaram ao uso do software MS Project ${ }^{\circledR}$ nas empresas A e C.

$\mathrm{O}$ único problema relatado pelas quatro empresas em relação à implementação dos novos equipamentos referiu-se aos ajustes usuais necessários durante as fases iniciais de produção. Para acelerar a implementação, as empresas A e C incluíram nos termos de aquisição de seus respectivos equipamentos a presença em suas instalações de um técnico do fabricante pelo prazo de duas semanas com o objetivo de treinar os operadores e técnicos locais e acompanhá-los durante a fase inicial de produção.
Em termos do processo global de TT, a empresa A mencionou um atraso resultante do processo de importação dos equipamentos, o que provocou um excessivo prazo de seis meses entre a emissão da ordem de compra e a chegada dos equipamentos na fábrica. A empresa $B$ reclamou da demora no processo de financiamento bancário o que retardou o processo de importação em mais de dois meses. As firmas C e D não reportaram qualquer atraso no processo de TT.

O impacto efetivo dos processos de TT no desempenho das empresas pôde ser avaliado por meio do exame dos resultados obtidos com cada uma das aquisições de equipamentos realizadas. As quatro firmas lançaram novos produtos no mercado que puderam efetivamente competir contra as importações de baixo custo. Essa afirmação pôde ser constatada por meio da verificação da participação de mercado, do faturamento e da lucratividade das empresas antes e após a implementação das transferências de tecnologia objeto deste estudo. Desse modo, todos os objetivos inicialmente traçados para os processos de TT foram alcançados. Todas as quatro empresas foram unânimes em destacar que, sem a adição dos novos equipamentos, suas respectivas capacidades de competir teriam sido adversamente afetadas.

Com relação a eventuais modificações nos processo de TT visando futuras aquisições, somete as empresas A e B manifestaram o desejo de fazer algumas modificações. A firma A deverá mudar a abordagem empregada para a liberação aduaneira das importações e a B procurará desenvolver as ações necessárias para minimizar o prazo de aprovação do financiamento bancário de suas importações.

Como ilustram os comentários feitos até este ponto, pode-se notar que existem muitas similaridades e algumas diferenças nas práticas de TT para as quatro empresas analisadas neste trabalho. Esse resultado indica uma reposta favorável à questão de pesquisa $1(Q P 1)$ porque é possível identificar um processo de TT típico para as empresas pesquisadas, o que é essencial para a utilização de referenciais estruturados para gerenciar esse processo. Esse procedimento típico para a TT inclui o seguinte:

- adoção de um objetivo estratégico comum para justificar a procura pela nova tecnologia (reforçar a posição competitiva da empresa para enfrentar a forte concorrência de artigos importados de baixo custo, por meio do desenvolvimento de novos produtos);

- identificação da aquisição de novos equipamentos como fonte básica da nova tecnologia necessária;

- utilização dos fornecedores como fonte básica de tecnologia para a nova aquisição;

- utilização de visitas a feiras de negócios e de contatos frequentes com os fornecedores (ou seus representantes) como forma principal de obter informações sobre a nova tecnologia; 
- participação ativa dos Gerentes Gerais na identificação, seleção, negociação e implementação da nova tecnologia;

- utilização de especificações técnicas, visitas a competidores (para tomar contato com a nova tecnologia) e experiência anterior favorável com os fornecedores (e seus representantes) são os critérios básicos para identificar potenciais novas tecnologias;

- adoção de um procedimento comum de seleção de fornecedores baseado na melhor solução técnica seguida por uma análise das condições comerciais;

- uso extensivo do representante local do fornecedor durante os processos de negociação faca a face, por e-mail ou telefone;

- utilização de um planejamento prévio para a implementação da nova tecnologia devidamente aprovada pelo Gerente Geral;

- contratação e treinamento de mão de obra adicional para operar a nova tecnologia;

- validação da adequação da nova tecnologia adquirida com base nos resultados reais do negócio comparados com os objetivos e metas inicialmente estabelecidos;

- pouca utilização de recursos da tecnologia da informação para suportar o processo de TT (restrito à utilização de e-mails e do software MS Project $\left.{ }^{\circledR}\right)$.

\section{Comparação com o modelo Stage-gate}

Devido ao fato de um processo comum de TT ter sido identificado para as empresas têxteis pesquisadas, a próxima questão de pesquisa $(Q P 2)$ levanta a possibilidade de se utilizar um modelo do tipo Stagegate para gerenciar aquele processo. Para avaliar essa opção, as práticas de TT das quatro empresas foram analisadas usando como referencial o modelo Stage-gate como proposto por Jagoda e Ramanathan (2003, 2005, 2009) e Jagoda, Maheshwari e Lonseth (2010).

Dentro dessa abordagem foi possível identificar que no stage 1 - identificar a oportunidade e respectiva tecnologia - nenhuma das quatro empresas utilizou comitês diretores de TT e nem elaborou roteiros de seleção. De fato, as quatro firmas pesquisadas identificaram uma prioridade estratégia comum que foi aumentar a sua competitividade por meio da adoção da diferenciação em produtos para enfrentar uma forte concorrência por parte de produtos importados de baixo custo. Em adição a isso, elas puderam definir de maneira bastante precisa que tipos de novos produtos seriam necessários para competir no mercado, produtos esses que serviram de base para estabelecer os requisitos principais para os novos equipamentos (tecnologia) a serem adquiridos. Contudo, foi interessante notar que as entrevistas demonstraram que essas especificações foram realizadas como parte do processo de reposicionamento estratégico das empresas e não como uma etapa inicial do processo de transferência de tecnologia. Quando a busca por novos equipamentos efetivamente se iniciou (stage 2) a tecnologia necessária para a diversificação de produto já estava bem definida. Com base nessas considerações, é possível assumir que, nos casos analisados, os stages 1 e 2 tenham sido desenvolvidos simultaneamente. $\mathrm{O}$ stage 2 - busca focada da tecnologia - está presente nos quatro casos estudados, já que um conjunto bastante claro de especificações foi preparado com relação à tecnologia necessária e os potenciais fornecedores foram identificados e contatados. Aqui a identificação dos fornecedores potenciais difere das práticas recomendadas pelo modelo Stage-gate, o que resulta do comportamento bastante conservador observado nas empresas têxteis do Brasil. Assim, ao invés de elaborar um perfil desejado para os fornecedores levando-se em conta as características da tecnologia necessária, suas estratégias de negócios e outras habilidades desejadas, as quatro empresas identificaram as possíveis fontes da tecnologia que necessitavam com base em experiências passadas favoráveis com tipos similares de equipamentos. Essa abordagem simplifica o conteúdo do stage 2 para as empresas têxteis brasileiras porque a pesquisa da tecnologia desejada fica limitada a uma lista estreita de possibilidades: aqueles fornecedores que tenham sido considerados como fontes confiáveis de equipamentos com desempenho bastante favorável no passado recente.

O gate 2- confirmação do projeto - é informalmente desenvolvido pelos Gerentes Gerais das quatro empresas na medida em que eles participam pessoalmente da seleção das tecnologias a serem propostas a um reduzido número de fornecedores. Como já se mencionou, as quatro empresas empregam um critério comum para selecionar o fornecedor: inicialmente identifica-se aquele que tenha apresentado a melhor solução técnica e, em seguida, se discute com ele as condições comerciais. Somente a empresa C tem uma condição adicional, na medida em que ela também considera a padronização de equipamentos em seu parque fabril. Como se observa aqui, o processo de seleção do fornecedor da tecnologia é mais simples do que o previsto pelo modelo Stage-gate porque: a) as alternativas de seleção são muito limitadas; b) o processo de decisão já é bem conhecido pelo comprador e pelo fornecedor; e c) o Gerente Geral toma a decisão final baseado em seu exclusivo critério.

O stage 3 - negociação da tecnologia - é também realizado pelos Gerentes Gerais que assumem 
pessoalmente a íntegra do processo de negociação. As negociações das empresas A e B são feitas inteiramente por meio dos representantes locais do fornecedor do equipamento selecionado para a TT. O processo de negociação envolve a definição das especificações finais dos equipamentos e das condições comerciais mutuamente aceitas por ambas as partes. A empresa $\mathrm{C}$ adota um processo similar, porém com negociações desenvolvidas diretamente com o fabricante internacional do equipamento escolhido. Devido a seu processo peculiar de aquisição de equipamentos usados, a empresa D interage diretamente com seu fornecedor, geralmente uma firma de maior porte localizada nas proximidades. Neste caso, as negociações são informais e desenvolvidas de "dono" para "dono". As observações feitas em campo parecem indicar que os procedimentos adotados na negociação da TT seguem em termos gerais o que o modelo Stage-gate estipula, porém sem envolver tantos detalhes e especificidades.

O gate 3 - finalização e aprovação do contrato de fornecimento - é formalmente desenvolvido pelas empresas A, B e C na medida em que elas emitem uma ordem de compra que contém todos os detalhes que foram negociados como parte do stage 3. Em geral, as especificações técnicas finais e a proposta comercial mutuamente aceita são mencionadas nessa ordem de compra. A aceitação desse documento pelo fornecedor da tecnologia é o seu reconhecimento de que todas as negociações estão finalizadas e seus termos aceitos por ambas as partes. Assim, no gate 3 , a ordem de compra que é aceita pelo fornecedor da tecnologia é utilizada no lugar de um contrato formal de transferência de tecnologia, tornando o processo de TT investigado mais simples do que o preconizado no modelo Stage-gate.

No stage 4 - preparação de um plano de implementação para a TT - as empresas A, B e C prepararam planos de implementação detalhados envolvendo uma lista completa de tarefas a serem executadas antes da chegada dos equipamentos, incluindo-se aí os planos de treinamento para a mão de obra adicional necessária. Equipes de implementação multifuncionais foram estabelecidas como os respectivos Gerentes Gerais atuando como gerentes de projeto em tempo parcial. Em contraste, a empresa D preparou somente um cronograma informal contendo datas previstas para os eventos principais, pois seu Gerente Geral indicou que um cronograma global seria suficiente para esse propósito. De fato, comparando os procedimentos investigados com os recomendados pelo modelo Stage-gate, foi possível identificar que alguns aspectos relevantes não são considerados pelas empresas têxteis: elas não consideram as eventuais alterações organizacionais, mudanças no fluxo de trabalho e adaptações no sistema de gestão para acomodar a transferência de tecnologia já que os novos equipamentos, em realidade, representavam apenas uma melhoria do seu nível tecnológico sem impacto decisivo sobre aqueles itens.

$\mathrm{O}$ gate 4 - aprovação do plano de implementação - também estava presente nas quatro empresas pesquisadas. Nas firmas A, B e C, o planejamento detalhado foi revisado e aprovado pelos respectivos Gerentes Gerais, que são, em última instância, os responsáveis pelos projetos de TT. Na empresa $\mathrm{D}$, a revisão e aprovação fez parte intrínseca do processo de desenvolvimento do plano, uma vez que o próprio Gerente Geral encarregou-se da sua elaboração. Contudo, o grau de discussão e de formalização para a aprovação do plano de implementação da TT é bastante baixo como resultado da participação intensiva e extensiva dos Gerentes Gerais ao longo de todo o processo de TT. Assim, o gate 4 refere-se tão somente a uma reunião de revisão operacional com a equipe de implementação da TT, cujo objetivo é verificar se tudo foi devidamente planejado para receber e instalar os novos equipamentos.

O stage 5 - implementação efetiva da TT - basicamente seguiu o que o modelo Satgegate especifica para essa fase do processo de TT. Contudo, as atividades aqui consideradas foram, outra vez, bastante simplificadas por que a TT envolvia somente a aquisição de equipamentos. Essa abordagem elimina a necessidade de se considerar tarefas tais como desenvolver uma análise de make vs. buy ou de manter contato com as autoridades locais para acompanhar possíveis mudanças na legislação. Em termos de desempenho na implementação, os entrevistados das empresas $\mathrm{C}$ e D relataram que não houve reclamações já que os resultados foram satisfatórios, sem informações de atrasos ou problemas. Por outro lado, as firmas A e B indicaram atrasos significativos em suas implementações. A empresa A teve muitas dificuldades com o desembaraço de suas importações na Alfândega, o que atrasou substancialmente a liberação dos equipamentos, sua instalação e início de operação. De maneira análoga, a empresa B enfrentou problemas com a aprovação do financiamento bancário necessário para financiar a aquisição dos seus equipamentos, o que também gerou atrasos na chegada dos equipamentos na fábrica, prejudicando, por consequência, a data objetivo para o seu efetivo início de produção. O gate 5 - auditoria da implementação - foi informalmente desenvolvido nas empresas A e B como resultado das dificuldades de implementação que experimentaram. Os problemas encontrados foram devidamente registrados por ambas as equipes de implementação e considerados como fontes de possíveis melhorias para o futuro. As empresas $\mathrm{C}$ e $\mathrm{D}$ não realizaram qualquer avaliação da implementação, pois não 


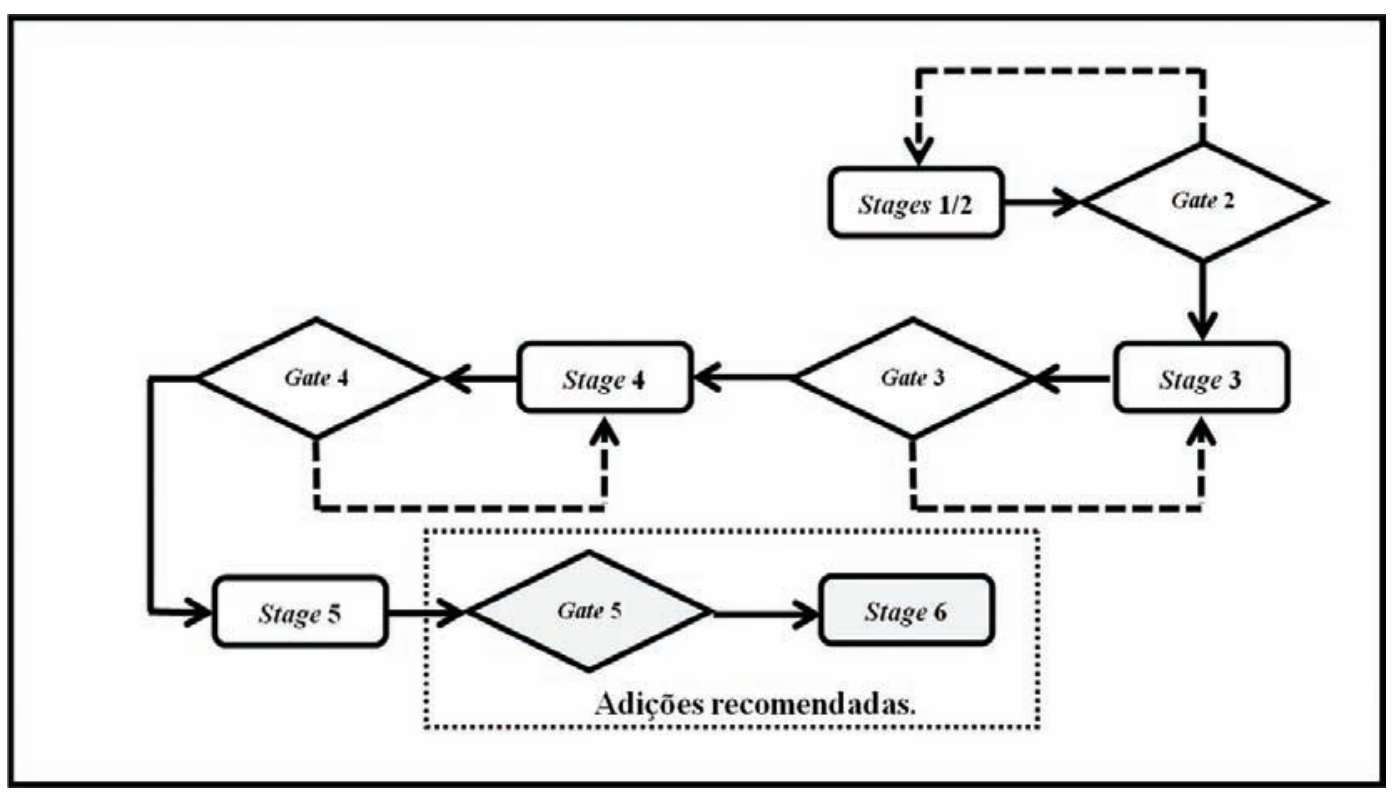

Figura 2. Resumo do modelo de TT de Jagoda e Ramanathan adaptado para as empresas têxteis, incluindo as adições recomendadas.

havia problemas maiores a serem considerados. É interessante notar que o gate 5 só se efetivou como uma resposta a problemas sérios enfrentados na implementação da TT. Quando os problemas não existiram, a auditoria da implementação não foi realizada. Esse cenário torna-se uma oportunidade para uma melhoria na transferência de tecnologia da indústria têxtil já que a execução do gate 5 , em qualquer circunstância, poderia tornar-se fonte de avanço contínuo no processo de TT.

No stage 6 - avaliação do impacto da transferência de tecnologia realizada -, nenhuma avaliação formal do impacto da TT foi feita pelas quatro empresas pesquisadas. Quando perguntados sobre os resultados efetivos que foram obtidos pelos projetos de TT considerados, todos os entrevistados indicaram que os resultados obtidos pelas suas respectivas empresas em termos de participação de mercado, crescimento de vendas e lucratividade mostravam que os objetivos estabelecidos para os projetos de TT haviam sido alcançados. Contudo, essa informação foi obtida dos respectivos sistemas de informações gerenciais e não como parte de uma análise em consonância com o que preconiza o stage 6. Dessa forma, para todos os fins práticos, o processo de TT para as quatro empresas pesquisadas se encerra no stage (ou gate) 5. Levando-se em conta a importância de confirmar os resultados planejados para a TT, seria recomendável que as empresas têxteis incorporassem a análise proposta pelo stage 5 em seus processos de TT.

No gate 6 - atividades pós-TT -, o objetivo é decidir se a empresa continua a utilizar a tecnologia transferida ou busca outra, mais eficiente. No caso das quatro empresas pesquisadas, essa questão não se aplica porque todas elas basearam-se em experiência anterior favorável como base para a seleção de seu fornecedor de tecnologia. Portanto, havia uma probabilidade bastante reduzida de que resultados indesejados acontecessem em decorrência do processo de TT utilizado.

Como resultado da análise feita, é possível assumir que a questão de pesquisa $2(Q P 2)$ poderia ser favoravelmente respondida, pois o referencial Stage-gate, como proposto por Jagoda e Ramanathan, poderia ser adequadamente usado para gerenciar o processo de TT na indústria têxtil, desde que algumas adaptações sejam consideradas. Com base nos resultados das pesquisas aqui realizadas, as práticas de TT utilizadas pelas empresas têxteis não estão de acordo com a utilização dos stages 1 e 6 e dos gates 1,5 e 6 . Contudo, para o fortalecimento do processo de TT por meio da adoção de uma abordagem de melhoria contínua, recomenda-se a utilização do gate 5 e do stage 6, uma vez que proporcionariam: a) uma avaliação real do desempenho da implementação da TT para gerar melhorias adicionais (gate 5) e b) uma avaliação dos resultados da TT comparados aos objetivos inicialmente planejados (stage 6), o que também seria fonte de futuros avanços. Esse cenário responde favoravelmente a questão de pesquisa 3 (QP3), desde que as recomendações feitas sejam incluídas no referencial Stage-gate modificado a ser utilizado pelas empresas do setor têxtil. A Figura 2 mostra o modelo Stage-gate para as empresas têxteis com as recomendadas adições do gate 5 e stage 6. 


\section{Conclusões}

O objetivo central deste trabalho foi o de contribuir com o aumento da competitividade das

empresas têxteis brasileiras, gerando conhecimentos teóricos e direcionamentos práticos para que elas possam vir a usar um modelo Stage-gate para melhorar seus processos de TT destinados a reforçar suas bases tecnológicas, para poderem enfrentar uma forte concorrência imposta por produtos importados. Para isso, foram considerados quatro fabricantes de tecidos com projetos de TT similares. Em adição aos resultados da pesquisa realizada e já relatados anteriormente, alguns comentários finais podem ser feitos para concluir este trabalho.

Primeiramente é relevante mencionar que os processos de transferência de tecnologia aqui referidos devem ser considerados como de baixa complexidade quando comparados a outros que envolvem tecnologia mais sofisticada. Tal fato permite fazer a transferência de tecnologia de maneira relativamente mais simples e menos exigente em termos de processamento de informações e de colaboração. Ainda assim, é possível identificar uma contribuição teórica do processo de TT pesquisado à implementação da estratégia de manufatura das empresas têxteis. De fato, todas as empresas pesquisadas identificaram a necessidade de atualizar suas respectivas tecnologias de fabricação como uma resposta às pressões competitivas oriundas das importações de baixo custo. Uma vez que a tecnologia adequada (equipamento) foi identificada, foi um processo típico de TT que garantiu sua adequada implementação. Assim, esta pesquisa também permitiu identificar uma adequação entre as estratégias selecionadas pelas empresas têxteis, suas necessidades competitivas e as tecnologias de manufatura que elas usam, como sugerido por Congden (2005).

Ainda, os resultados aqui obtidos sugerem que é possível identificar um processo de TT típico que é empregado pelas empresas têxteis brasileiras, o que é essencial para a utilização de um referencial estruturado para gerenciá-lo. Em adição, os resultados da pesquisa aqui relatados confirmam muitos pontos como mostrados na literatura em relação a práticas comuns de TT no setor têxtil. Contudo, foram encontradas também algumas diferenças. De início, o processo típico de TT que foi identificado difere, em vários aspectos, do procedimento genérico de TT sugerido por Braga Junior, Antunes e Pio (2009): os autores não mencionam o peculiar e intenso envolvimento dos Gerentes Gerais ao longo de todo o processo e nem a utilização de experiência passada favorável como fator decisivo na seleção da tecnologia. Da mesma forma, Lima (2007) menciona que as melhorias de tecnologia implementadas têm sido focadas principalmente na reposição de equipamentos obsoletos. Como relatado, foi possível identificar que a decisão de adquirir nova tecnologia de fabricação teve origem no reposicionamento estratégico das empresas como resposta às suas necessidades competitivas e não na necessidade de substituir ativos em fim de vida. Braga Junior, Antunes e Pio (2009) propõem que, nas grandes e médias empresas, o processo de aquisição de tecnologia é conduzido por um comitê composto por representantes da alta administração, da supervisão e do departamento de criação. Na pesquisa realizada, não se obteve qualquer evidência desses comitês em qualquer das empresas analisadas.

Sob o aspecto da contribuição à prática da TT nas empresas têxteis, o referencial apresentado e suas discussões poderiam vir a ser usados pelos profissionais das empresas para melhorar o gerenciamento de seus respectivos processos de TT. De fato, conhecendo como essas práticas são presentemente desenvolvidas e como elas poderiam ser melhoradas por meio da utilização de um modelo de transferência de tecnologia, os profissionais da indústria teriam à sua disposição subsídios valiosos para a condução mais efetiva dos seus processos de TT.

Na pesquisa desenvolvida, foi possível verificar que um modelo Satge-gate poderia ser utilizado como um referencial para propiciar um melhor gerenciamento do processo de TT na indústria têxtil, contribuindo de maneira relevante para o aumento da competitividade dessas empresas. Especificamente, o modelo proposto por Jagoda e Ramanathan mostrou-se uma alternativa possível para alcançar esse objetivo, desde que algumas adaptações sejam feitas, como já sugerido. É ainda relevante mencionar que os processos de TT analisados dependem de maneira significativa do relacionamento comprador-vendedor. Por isso, com base em Rahman e Bennett (2009), uma recomendação prática para as empresas que desenvolvem processos de TT é que elas desenvolvam e mantenham sólidos relacionamentos com seus supridores de tecnologia, porque, ao fazerem isso, elas poderiam esperar um nível mais elevado de desempenho ao adquirir e implementar uma nova tecnologia.

Como uma observação final, algumas limitações da pressente pesquisa podem ser destacadas. Primeiro, os resultados obtidos não devem ser generalizados porque eles foram baseados na análise de somente quatro empresas têxteis típicas, selecionadas por conveniência dos pesquisadores em função dos critérios previamente estabelecidos e já descritos. Em paralelo, os resultados não podem ser estendidos a outros segmentos industriais porque as prioridades competitivas e as práticas de transferência de tecnologia podem ser diferentes (contudo, o modelo Stage-gate poderia ser facilmente adaptado para acomodar adequadamente os processos de TT de outros segmentos industriais). Também surpreendeu a elevada semelhança observada entre as práticas de TT utilizadas pelas quatro empresas pesquisadas, 
mesmo considerando as diferenças de porte e de padrão competitivo existentes entre elas, fato que poderia ser mais amplamente explorado em pesquisas adicionais desenvolvidas especificamente para essa finalidade. Em conclusão, os resultados da pesquisa realizada devem ser considerados criteriosamente porque a amostra é limitada em tamanho e a pesquisa centrou seus estudos somente na indústria têxtil de uma região geográfica específica. Todavia, todas essas limitações poderiam vir a ser eliminadas por meio de trabalhos adicionais de pesquisa que pudessem vir a expandir os resultados aqui obtidos.

\section{Referências}

ASSOCIAÇÃO BRASILEIRA DA INDÚSTRIA TÊXTIL E DE CONFECÇÃO - ABIT. Perfil do setor: dados gerais do setor atualizados em 2012, referentes a 2011. São Paulo, 2012. Disponível em: 〈http://www.abit.org.br/ site/navegacao.asp?id_menu=1\&id_sub=4\&idioma=PT $>$. Acesso em: 9 ago. 2012.

AUDRETSCH, D. B. The entrepreneurial society. The Journal of Technology Transfer, v. 34, n. 3, p. 245-254, 2009. http://dx.doi.org/10.1007/s10961-008-9101-3

BARBIERI, J. C.; ÁLVARES, A. C. T. Estratégia de patenteamento e licenciamento de tecnologia: conceitos e estudo de caso. Revista Brasileira de Gestão de Negócios, v. 7, n. 17, p. 58-68, 2005.

BENNETT, D.; ZHAO, H. International technology transfer: perceptions and reality of quality and reliability. Journal of Manufacturing Technology Management, v. 15, n. 5, p. 410-415, 2004. http:// dx.doi.org/10.1108/17410380410540408

BRAGA JUNIOR, E.; ANTUNES, A. M. S.; PIO, M. J. O processo de transferência de tecnologia na indústria têxtil. Journal of Technology Management \& Innovation, v. 4, n. 1, p. 125-133, 2009.

BRYMAN, A. Research methods and organization studies. London: Routledge, 1995.

CHANG, T. et al. A case study for implementing a B2B collaborative information system: a textile case. Journal of Manufacturing Technology Management, v. 20, n. 3, p. 330-347, 2009. http:// dx.doi.org/10.1108/17410380910936783

CHICÁN, A. National and firm competitiveness: a general research model. Competitiveness Review: An International Business Journal, v. 18, n. 1-2, p. 20-28, 2008. http://dx.doi.org/10.1108/10595420810874583

CHOI, H. J. Technology transfer issues and a new technology transfer model. The Journal of Technology Studies, v. 35, n. 1, p. 49-57, 2009.

COCCIA, M. Spatial mobility of knowledge transfer and absorptive capacity: analysis and measurement of the impact within the geo-economic space. The Journal of Technology Transfer, v. 33, n. 1, p. 105-122, 2008. http://dx.doi.org/10.1007/s10961-007-9032-4

COLLINS, J.; HUSSEY, R. Business research methods. New York: McGraw-Hill, 2003.

CONGDEN, S. W. Firm performance and the strategic fit of manufacturing technology. Competitiveness
Review, v. 15, n. 1, p. 14-32, 2005. http://dx.doi. org/10.1108/10595420510818678

DI BENEDETTO, C. A.; CALANTONE, R. J.; ZHANG, C. International technology transfer: model and exploratory study in the People's Republic of China. International Marketing Review, v. 20, n. 4, p. 446-462, 2003. http:// dx.doi.org/10.1108/02651330310485171

ERENSAL, Y. C.; ALBAYRAK, Y. E. Transferring appropriate manufacturing technologies for developing countries. Journal of Manufacturing Technology Management, v. 19, n. 2, p. 158-171, 2008. http:// dx.doi.org/10.1108/17410380810847891

FREEMAN, C. The economics of industrial innovation. Harmondsworth: Penguin, 1974.

GIBSON, D. V.; SLIMOR, W. Key variables in technology transfer: a field study based on empirical analysis. Journal of Engineering and Technology Management, v. 8, n. 3-4, p. 287-312, 1991. http:// dx.doi.org/10.1016/0923-4748(91)90015-J

GUAN, J. C. et al. Technology transfer and innovation performance: evidence from Chinese firms. Technological Forecasting and Social Change, v. 73, n. 6, p. 666-678, 2006. http://dx.doi.org/10.1016/j.techfore.2005.05.009

IVARSSON, I.; ALVSTAM, C. G. International technology transfer through local business linkages: the case of Volvo trucks and their domestic suppliers in India. Oxford Development Studies, v. 32, n. 2, p. 241-260, 2004. http://dx.doi.org/10.1080/13600810410001699975

JAGODA, K.; RAMANATHAN, K. A stage-gate model for guiding international technology transfer. In: PORTLAND INTERNATIONAL CONFERENCE ON MANAGEMENT OF ENGINEERING AND TECHNOLOGY - PICMET, 2003, Portland, Oregon. Proceedings... 2003. CD-ROM.

JAGODA, K.; RAMANATHAN, K. Critical success and failure factors in planning and implementing international technology transfer: a case study from Sri Lanka. In: PORTLAND INTERNATIONAL CONFERENCE ON MANAGEMENT OF ENGINEERING AND TECHNOLOGY - PICMET, 2003, Portland, Oregon. Proceedings... 2005. CD-ROM.

JAGODA, K.; RAMANATHAN, K. Backward integration through international technology transfer: a case study from the textile industry of Sri Lanka. In: ADMINISTRATIVE SCIENCES ASSOCIATION OF CANADA - ASAC, 2009, Niagara Falls, Ontario. Proceedings... CD-ROM.

JAGODA, K.; MAHESHWARI, B.; LONSETH, $\mathrm{R}$. Key issues in managing technology transfer projects - experiences from a Canadian SME. Management Decision, v. 48, n. 3, p. 366-382, 2010. http://dx.doi.org/10.1108/00251741011037747

KUMAR, S.; ARBI, S. A. Outsourcing strategies for apparel manufacture: a case study. Journal of Manufacturing Technology Management, v. 19, n. 1, p. 73-91, 2007. http://dx.doi.org/10.1108/17410380810843462

LAGER, T.; FRISHAMMAR, J. Equipment supplier/user collaboration in the process industry: in search of enhanced operating performance. Journal of Manufacturing Technology Management, v. 21, n. 1, p. 698-720, 2010. http://dx.doi.org/10.1108/17410381011064003 
LIMA, M. S. O. O gás natural como alternativa energética para a indústria têxtil: vantagem competitiva ou estratégia de sobrevivência. 2007. 125 f. Dissertação (Mestrado em Engenharia de Produção)-Escola de Engenharia de São Carlos, Universidade de São Paulo, São Carlos, 2007.

LUCATO, W. C.; VIEIRA JUNIOR, M. As dificuldades da capitalização para as pequenas e médias empresas brasileiras. Produção, v. 16, n. 1, p. 24-33, 2006. http:// dx.doi.org/10.1590/S0103-65132006000100003

LOBO, M. S. S. H. Qualificações-chave na indústria têxtil brasileira - uma redefinição conceitual para as exigências de formação no Mercosul. In: ENCONTRO NACIONAL DE ENGENHARIA DE PRODUÇÃO - ENEGEP, 17., 1997, Gramado. Anais... Gramado: ABEPRO, 1997.

MALIK, K. Alternatives to validity. Knowledge: Creation, Diffusion, Utilization, v. 8, p. 509-520, 2002.

MILES, R.; SNOW, C. Organizational strategy, structure and process. New York: McGraw- Hill, 1978.

MILLER, A. A taxonomy of technological settings, with related strategies and performance levels. Strategic Management Journal, n. 9, p. 239-254, 1988. http:// dx.doi.org/10.1002/smj.4250090304

NAGAOKA, S. Does strong patent protection facilitate international technology transfer? Some evidence from licensing contracts of Japan Firms. Journal of Technology Transfer, v. 34, n. 2, p. 128-144, 2009. http://dx.doi.org/10.1007/s10961-007-9071-x

PATTON, M. Q. Qualitative evaluation and research methods. Newbury Park: Sage, 1990.

PAVIT, K. Sectoral patterns of technical change: Towards a taxonomy and a theory. Research Policy, v. 13, n. 6, p. 343-373, 1984. http://dx.doi. org/10.1016/0048-7333(84)90018-0

PORTER, M. E. What is strategy? Harvard Business Review, v. 74, n. 6, p. 61-78, 1996.

PROCHNIK, V. A cadeia têxtil: confecções perante os desafios da Alca e do acordo comercial com a União Européia. Economia, v. 4, n. 1, p. 53-83, 2003.

RAHMAN, A. A; BENNETT, D. Advanced manufacturing technology adoption in developing countries: the role of buyer-supplier relationships. Journal of Manufacturing Technology Management, v. 20, n. 8, p. 1099-1118, 2009. http://dx.doi.org/10.1108/17410380910997236
RANGEL, A. S.; SILVA, M. M.; COSTA, B. K. Competitividade da indústria têxtil brasileira. Revista de Administração e Inovação, v. 7, n. 1, p. 151-174, 2010.

REBENTISCH, E. S.; FERRETTI, M. A knowledgebased view of technology transfer in international joint ventures. Journal of Engineering Technology Management, v. 12, n. 1-2, p. 1-25, 1995. http://dx.doi. org/10.1016/0923-4748(95)00002-4

ROGERS, E. M.; TAKEGAMI, S.; YIN, J. Lessons learned about technology transfer. Technovation, v. 21, n. 4, p. 253-261, 2001. http://dx.doi.org/10.1016/ S0166-4972(00)00039-0

STOCK, G. N.; TATIKONDA, M. V. External technology integration in product and process development. International Journal of Operations and Productions Management, v. 24, n. 7, p. 642-665, 2004. http:// dx.doi.org/10.1108/01443570410541975

STOCK, G. N.; TATIKONDA, M. V. The join influence of technology uncertainty and inter-organizational interaction on external technology integration success. Journal of Operations Management, v. 26, n. 1, p. $65-80,2008$. http://dx.doi.org/10.1016/j. jom.2007.04.003

SUNG, T. K.; GIBSON, D. V. Knowledge and technology transfer: key factors and levels. In: INTERNATIONAL CONFERENCE ON TECHNOLOGY POLICY AND INNOVATION, 4., 2000. Proceedings... 2000. p. 4.4.1-4.4.9.

TAKAHASHI, V. P.; SACOMANO, J. B. Proposal of a conceptual model to analysis of success of technology transfer Project: study in pharmaceutical firms. Gestão \& Produção, v. 9, n. 2, p. 186-200, 2002.

TAKAHASHI, V. P. Transfer of technological knowledge: a multiple case study in the pharmaceutical industry . Gestão \& Produção, v. 12, n. 2, p. 255-269, 2005. http://dx.doi.org/10.1590/S0104-530X2005000200009

WAROONKUN, T.; STEWART, R. Barriers to the strategic adoption of revolutionary manufacturing processes. The Journal of Technology Transfer, v. 33, n. 6, p. 667-687, 2008. http://dx.doi.org/10.1007/s10961-007-9043-1

WILLIAMS, F.; GIBSON, D. V. Technology transfer: a communication perspective. Beverly Hills: Sage, 1990.

YIN, R. K. Case study research: design and methods. 4th ed. Newbury Park: Sage, 2009. 